Journal of Advanced Research in Fluid Mechanics and Thermal Sciences

\title{
Numerical Studies on Temperature and Material Flow During Friction Stir Welding using Different Tool Pin Profiles
}

\author{
M. D. Bindu ${ }^{1,}{ }^{*}$, P. S. Tide $^{2}$, A. B. Bhasi ${ }^{2}$ \\ Department of Mechanical Engineering, Research Scholar, Cochin University of Science and Technology, Kerala, India \\ Department of Mechanical Engineering, Faculty of Engineering, Cochin University of Science and Technology, Kerala, India
}

\begin{tabular}{l} 
ARTICLE INFO ABSTRACT \\
\hline
\end{tabular}

\section{Article history:}

Received 24 December 2020

Received in revised form 14 April 2021

Accepted 19 April 2021

Available online 22 May 2021

\begin{abstract}
A three-dimensional computational fluid dynamics (CFD) model has been developed to study the effect of tool pin profile on the material flow and temperature development in friction stir welding (FSW) of high specific strength AA 7068 alloy. Numerical simulations were carried out using a RNG k- $\varepsilon$ turbulence model. Three tool pin profiles, viz. cylindrical, conical and straight cylindrical threaded were considered for the simulation. The temperature distribution and material flow pattern obtained from the simulation were compared for different pin profiles. Simulation predicted better material mixing and highest peak temperature in weld joints produced with straight cylindrical tapered thread pin. Taking this as the optimised condition weld joints were fabricated using the straight cylindrical threaded pin with the same parametric combinations as in the simulation. Peak temperature measured in the experiment was less than that obtained by simulation. Hardness measurements taken at different weld regions has showed that about $71 \%$ of that of the base metal hardness is obtained with the threaded tool pin. The microstructure study revealed a defect free weld joint. Precipitates distributed in the microstructure indicate sufficient heat input to join the material without dissolving precipitates. The developed numerical model is helpful in optimising FSW process parameters.
\end{abstract}

Keywords:

AA 7068; Friction stirs welding; CFD; RNG k- $\varepsilon$ model; Tool pin profile

\section{Introduction}

Friction stir welding (FSW) is a solid-state welding method that has been developed for the joining of aluminum alloys. Aluminium and its alloys face problems related to melting and solidification like defect formation and solidification cracking during traditional welding processes. The absence of melting and solidification in FSW reduces the chances of defect formation. The acceptability of FSW for joining the precipitation hared enable alloys which are commonly referred to as non-weldable alloys is gaining momentum these days $[1,2]$.

The aluminium alloy AA 7068 was introduced in the year 2000. It has the highest specific strength and corrosion resistance among all aluminium alloys known till date [3]. Currently its applications are limited to connecting rods, auto sport gearbox actuators, wheel components and prosthetic limbs.

\footnotetext{
* Corresponding author.

E-mail address: mdbindudharmajan@gmail.com
}

https://doi.org/10.37934/arfmts.83.1.91104 
These components are processed either by casting or by forming routes. Aerospace industries use $7 x x x$ alloys for making structures [4]. AA 7068 can be used as a substitute for many aerospace materials in the 7xxx group that has lower strength and lower corrosion resistance [5]. Widening the application spectrum of AA 7068 requires a good joining technique. Since the fusion welding of $A A$ 7068 is difficult, FSW may be considered for joining this alloy.

Developing joining process for a new alloy necessitate knowledge of all process parameters involved and their optimal combination to produce defect free, strong welds. To gather the information regarding these parameters, a large number of experimental trials are required and this process is resource intensive. Numerical simulation based on finite volume and finite element method (FEM) is a convenient approach for the optimization of FSW [6].

In FSW, welding takes place when a non - consumable rotating tool with a protruded part known as 'pin' moves over the workpiece. Here, the heat is generated in two steps. First the rotating pin penetrates the workpieces to be joined. The friction between the pin and the work piece and the plastic deformation of the workpiece generate heat. In the second phase the rotating shoulder touches the workpiece surface and churns the material below generating heat. $80 \%$ of the total heat is contributed by the interaction between shoulder and workpiece. The heat developed determines the ease with which the tool moves in the workpiece in FSW. Besides tool pin and shoulder, the rotational speed, tool traverse speed, axial load on the tool, and tool tilt angle are the factors that control the heat input in FSW [7].

The heat input and material flow decide the final microstructure of the FSW joint. In FSW, peak temperature may reach as high as $90 \%$ of the melting temperature. Higher temperatures developed in the FSW of precipitation hardened alloys may cause dissolution of precipitates and will eventually reduce its strength. Thus, temperature should not be too high. On the other hand, temperature should be high enough to soften the workpiece material so as the tool can move and rotate through the material smoothly avoiding tool breakage. Thus, the input temperature should not be too high or too low. The temperature and the material flow depend mostly on the tool design [8].

The tool design in FSW ensures that 1) the tool provide necessary temperature and strain rate during FSW 2) the design is simple to provide ease of manufacture 3) the design is simple to provide ease of retraction after welding. Since the pin control the initial heat generation and material stirring, pin profile is critical in FSW tool design. Tool pin shape has undergone several changes since the development of FSW in the year 1991. The very basic design i.e., cylindrical tool was found to create tunneling defects [9]. To avoid this defect formation, hexagonal and fluted tools were developed. These shapes produce a pulsating action that will improve stirring. Tamadon et al., [9] used Bobbin tool to improve material flow. Thus, material mixing is a key factor to get defect free welds. From the literature it is understandable that a sound joint is produced when a properly designed tool combined with correct welding speed, tool rotational speed and axial force is used for the FSW. Depending on the characteristics of the workpiece the numerical values of these parameters are different [11].

The present study is aimed at developing a 3D CFD model for investigating the effect of tool pin profile on the thermo mechanical behaviour of FSW of $6 \mathrm{~mm}$ thick AA 7068-T6 alloy. Three tool pin profiles, viz. cylindrical, conical and threaded are considered here. A finite volume based CFD code of commercial software ANSYS is used for this simulation to optimize the pin profile. The developed CFD model can be further utilized to determine the effect of the other parameters involved and optimize them accordingly. 


\section{Computational Methodology}

\subsection{Governing Equations}

The AA 7068-T6 material is considered as steady, incompressible, non-Newtonian and viscoplastic fluid. The equations of mass conservation, energy conservation and momentum conservation are used to solve the thermal and flow field. The equation for conservation of mass is given by

$\frac{\partial u}{\partial x}+\frac{\partial v}{\partial y}+\frac{\partial w}{\partial z}=0$

$u, v$, and $w$ are components of welding velocity in $x, y$ and $z$ directions. The conservation of momentum or Navier-Stokes equation is given by

$\frac{\partial u}{\partial t}+u \frac{\partial u}{\partial x}+v \frac{\partial u}{\partial y}+w \frac{\partial u}{\partial y}=-\left(\frac{1}{\rho}\right) \frac{\partial p}{\partial x}+\mu\left(\frac{\partial^{2} u}{\partial x^{2}}+\frac{\partial^{2} u}{\partial y^{2}}+\frac{\partial^{2} u}{\partial z^{2}}\right)$

$\frac{\partial v}{\partial t}+u \frac{\partial v}{\partial x}+v \frac{\partial v}{\partial y}+w \frac{\partial v}{\partial y}=-\left(\frac{1}{\rho}\right) \frac{\partial p}{\partial y}+\mu\left(\frac{\partial^{2} v}{\partial x^{2}}+\frac{\partial^{2} v}{\partial y^{2}}+\frac{\partial^{2} v}{\partial z^{2}}\right)$

$\frac{\partial w}{\partial t}+u \frac{\partial w}{\partial x}+v \frac{\partial w}{\partial y}+w \frac{\partial w}{\partial y}=-\left(\frac{1}{\rho}\right) \frac{\partial p}{\partial z}+\mu\left(\frac{\partial^{2} w}{\partial x^{2}}+\frac{\partial^{2} w}{\partial y^{2}}+\frac{\partial^{2} w}{\partial z^{2}}\right)$

$\mathrm{P}$ is the pressure of the flow field, $\rho$ is the density of the fluid and $\mu$ is the viscosity of the fluid. Energy equation is

$C_{p}\left(u \frac{\partial T}{\partial x}+v \frac{\partial T}{\partial y}+w \frac{\partial T}{\partial y}\right)=k\left(\frac{\partial^{2} T}{\partial x^{2}}+\frac{\partial^{2} T}{\partial y^{2}}+\frac{\partial^{2} T}{\partial z^{2}}\right)+S_{I}+S_{b}$

where $C_{p}$ is the specific heat capacity, $k$ is the thermal conductivity; $T$ is the temperature, $S_{i}$ and $S_{b}$ heat generated due to friction and plastic deformation respectively. Heat generation equation for the cylindrical tool is given by Gadakh and Adepu [12] as

$S_{I}=\frac{2}{3} \pi \omega \tau_{\text {contact }}\left(R_{\text {shoulder }}^{3}-R_{\text {pin }}^{3}\right)$

where $\omega$ is the tool rotational speed $R$ shoulder is the shoulder radius and $R$ pin pin radius

$\tau_{\text {contact }}=f \times \frac{F}{\text { projected area }}$

where $F$ is the axial load applied to the tool and $f$ is the coefficient of friction.

The three profiles considered in this study have same shoulder radius, pin bottom radius and height. Hence, Eq. (6) is used for all three models.

$S_{b}=\gamma \bar{\varepsilon} \sigma_{e}$

where $\gamma$ is the conversion factor for mechanical energy into heat energy (in this model $\gamma$ is taken as $0.7, \bar{\varepsilon}$ effective strain and $\sigma_{\mathrm{e}}$ effective stress. 


\subsection{Turbulence Modeling}

The flow of material under the tool shoulder is highly swirling in nature. RNG $k-\varepsilon$ turbulence flow model is chosen for solving the turbulence quantities since it is capable of solving swirling flows [13]. For flow analysis involving complex geometries RNG k- $\varepsilon$ model is better than standard $k-\varepsilon$ models [14].

The governing equations for turbulent kinetic energy $(k)$ and turbulent energy dissipation rate $(\varepsilon)$ are given in Eq. (9) and Eq. (10) [15].

$\frac{\partial}{\partial \mathrm{t}}(\rho k)+\frac{\partial}{\partial \mathrm{x}_{i}}\left(\rho k u_{i}\right)=\frac{\partial}{\partial \mathrm{x}_{j}}\left(\alpha_{k} \mu_{t} \frac{\partial \mathrm{k}}{\partial \mathrm{x}_{j}}\right)-\rho \overline{u_{\imath}^{\prime} u_{\jmath}^{\prime}} \frac{\partial \mathrm{u}_{j}}{\partial \mathrm{x}_{i}}-\rho \varepsilon$

$\frac{\partial}{\partial \mathrm{t}}(\rho \varepsilon)+\frac{\partial}{\partial \mathrm{x}_{i}}\left(\rho \varepsilon u_{i}\right)=\frac{\partial}{\partial \mathrm{x}_{j}}\left(\alpha_{\varepsilon} \mu_{t} \frac{\partial \varepsilon}{\partial \mathrm{x}_{j}}\right)-C_{1 \varepsilon} \frac{\varepsilon}{k} \rho \overline{u_{\imath}^{\prime} u_{\jmath}^{\prime}} \frac{\partial \mathrm{u}_{j}}{\partial \mathrm{x}_{i}}-C_{2 \varepsilon} \rho \frac{\varepsilon^{2}}{k}-R_{\varepsilon}$

The effective viscosity $\left(\mu_{t}\right)$ by considering the effect of swirl is

$$
\begin{aligned}
& \mu_{t}=\rho C_{\mu} \frac{k^{2}}{\varepsilon} f\left(\alpha_{s}, \Omega, \frac{k}{\varepsilon}\right) \\
& R_{\varepsilon}=\frac{C_{\mu} \rho \eta^{3}\left(1-\eta / \eta_{0}\right)}{1+\beta \eta^{3}} \frac{\varepsilon^{2}}{k}
\end{aligned}
$$

The closure coefficients are, $\alpha_{k}=1.393, \alpha_{\varepsilon}=1.393, C_{\mu}=0.0845, \alpha_{s}=0.07, \eta_{0}=4.38$ and $\beta=0.012$

$\eta=S k / \varepsilon$

where, $S$ is the modulus of the mean rate-of-strain tensor and given by

$$
\begin{aligned}
& S=\left(2 S_{i j} S_{i j}\right)^{\frac{1}{2}} \\
& S_{i j}=\frac{1}{2}\left(\frac{\partial \bar{u}_{i}}{\partial x_{j}}+\frac{\partial \bar{u}_{j}}{\partial x_{i}}\right)
\end{aligned}
$$

$\Omega$ is the characteristic swirl number, and $C_{1 \varepsilon}=1.42$ and $C_{2 \varepsilon}=1.68$ are the model constants.

\subsection{Constitutive Equations}

The friction stir welding process is very much similar to a hot deformation process where the viscosity varies with temperature and strain rate. Hence the determination of viscosity is a difficult task. In the present analysis viscosity is expressed as a function of effective stress and strain rate and expressed as [16]

$\mu=\frac{\sigma_{e}}{3 \bar{\varepsilon}}$ 
where

$\sigma_{e}=1 / \alpha \sinh ^{-1}(Z / A)^{\frac{1}{n}}$

where $\mathrm{Z}$ is the Zener- Holloman parameter which is a function of material strain and temperature

$Z=\bar{\varepsilon} \exp \left(\frac{Q}{R T}\right)$

$Q$ is the activation energy for deformation, $R$ is the gas constant and $T$ is the temperature. $A, \alpha$, and $n$ are material constants $A=1.63 \times 10^{13} \mathrm{~s}-1, \alpha=(1 / 60.7) / \mathrm{MPa}, \mathrm{n}=5.33, \mathrm{Q}=191 \mathrm{~kJ} / \mathrm{mol}$.

\subsection{Material Properties}

The chemical composition of AA 7068-T6 are given in Table 1.

Table 1

Chemical Composition (wt. \%)

\begin{tabular}{|c|c|c|c|c|c|c|c|c|c|}
\hline $\mathrm{Si}$ & $\mathrm{Fe}$ & $\mathrm{Cu}$ & $\mathrm{Mn}$ & $\mathrm{Mg}$ & $\mathrm{Cr}$ & $\mathrm{Ni}$ & $\mathrm{Zn}$ & $\mathrm{Ti}$ & $\mathrm{Al}$ \\
\hline 0.14 & 0.19 & 2.4 & 0.03 & 3.03 & 0.05 & 0.007 & 8.3 & 0.05 & 85.51 \\
\hline
\end{tabular}

The properties of alloy used in the study vary with temperature. Temperature dependent property values are not available for AA 7068 -T6. These values are obtained by comparing the room temperature property values of $A A 7075$ and $A A$ 7068, and then use that ratio to calculate temperature dependent properties of AA 7068-T6. Properties of AA 7075-T6 is taken from Mills [17]. The calculated values of AA 7068-T6 are given in Table 2.

Table 2

Material properties

\begin{tabular}{llll}
\hline Temperature $(\mathrm{K})$ & Density $\left(\mathrm{kg} / \mathrm{m}^{3}\right)$ & Thermal Conductivity $(\mathrm{W} / \mathrm{mK})$ & Specific Heat $(\mathrm{J} / \mathrm{kg} \mathrm{K})$ \\
\hline 473 & 2814 & 137.68 & 1107.65 \\
573 & 2794 & 135.59 & 1130.72 \\
673 & 2768.6 & 137 & 1120 \\
773 & 2743.2 & 137 & 1269 \\
\hline
\end{tabular}

The exact variation of friction coefficient $(f)$ with temperature is not evaluated for AA 7068 alloy. Chen et al., [18] defined $f$ as temperature dependent parameter and in this simulation, the same approach is followed.

\subsection{Computational Domain and Boundary Conditions}

The calculations were performed over a rectangular shaped domain formed by joining two workpieces of dimensions $100 \mathrm{~mm} \times 50 \mathrm{~mm} \times 6 \mathrm{~mm}$ in the butt configuration (Figure 1). As the entire domain is considered fluid, the solid tool is not included in this model. The tool pin impression is made in the computational domain and its plunging depth of $5.75 \mathrm{~mm}$ is given.

Three different pin profiles are considered here - cylindrical pin, cylindrical taper (conical) and straight cylindrical threaded. The pin length and pin diameter are $5.75 \mathrm{~mm}$ and $6 \mathrm{~mm}$ respectively. The diameter of the shoulder is $20 \mathrm{~mm}$. The pin - shoulder part for the different configuration is given in Figure 2. For the purpose of identification of the different configurations, model numbers are 
assigned as shown in the bracket. i.e., conical C1, cylindrical C2 and straight cylindrical threaded C3. The same numbers are used to represent the profiles in the coming sessions.

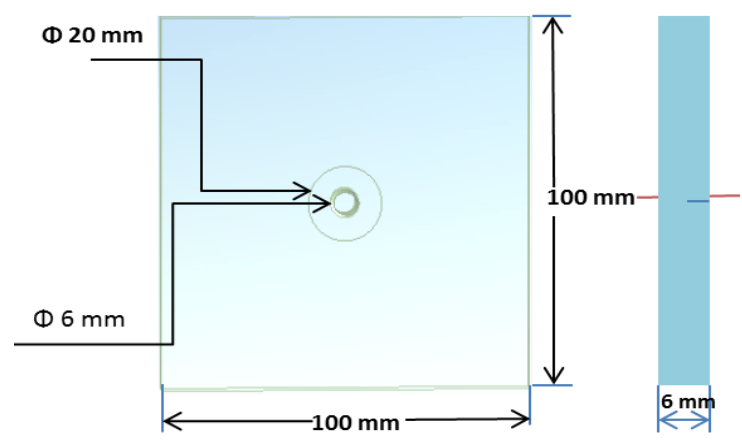

Fig. 1. Computational Domain

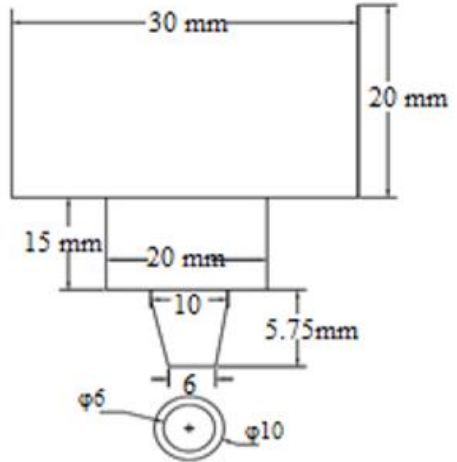

Conical (C1)

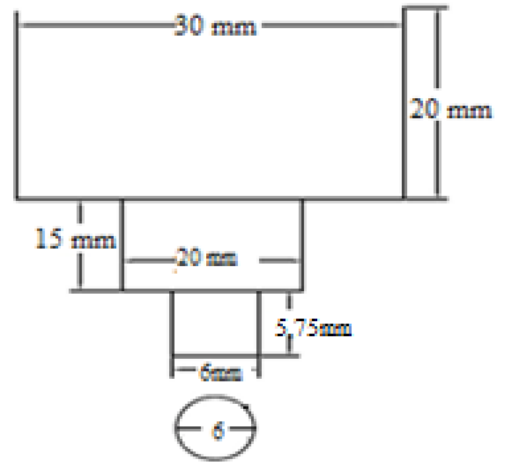

Cylindrical (C2)

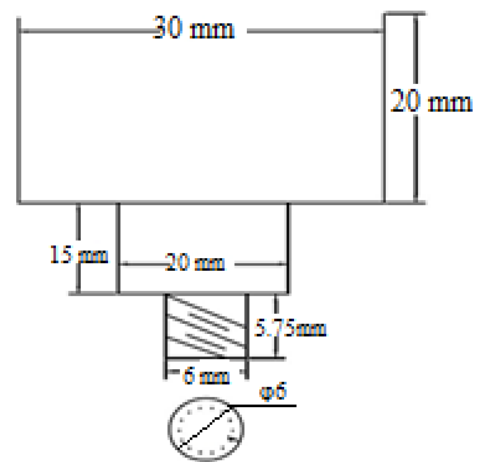

Straight cylindrical Threaded (C3)

Fig. 2. Pin Profiles used in the simulation with dimensions

Approximately 1.8 million cells were used for meshing the domain. Hexahedral meshing scheme was used for $\mathrm{C} 1$ and C2. During FSW, the pin rotates and moves along the joint line. The straight faces of the models $\mathrm{C} 1$ and $\mathrm{C} 2$ causes a circulatory motion for the material around the pin. Here the metal flows perpendicular to the cell face of the hexahedral meshes which is preferable. Calculation accuracy depends on making the angle between face-normal and the flow direction as small as possible if the flow is not perpendicular to the cell face. In C3 model the thread pitch moves the material through a spiral path. Here flow is not perpendicular to the cell face. To minimize the angle between face-normal and the flow direction, mesh scheme is changed to tetrahedral scheme. A closer view of the mesh used for each model is shown in Figure 3.

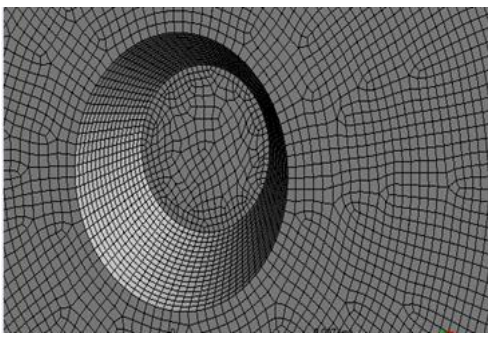

(a)

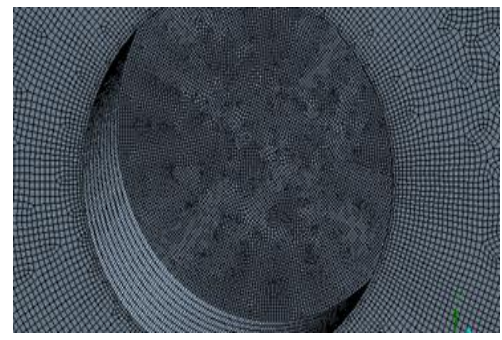

(b)

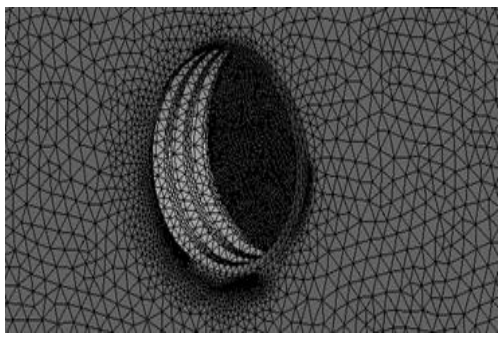

(c)

Fig. 3. Closer view of the mesh (a) C1, (b) C2, (c) C3 
The inlet, sides, top and bottom of the weldment were all moving wall and assumed to be approaching the stationary rotating tool with a velocity equal to the welding speed in a direction opposite to the welding direction. 'Pressure outlet' condition is given at the outlet. During the welding process heat loss occurs by the means of convection and radiation. Radiation effects are neglected in this simulation. The inlet, top, bottom and sides are under translational motion at the welding speed of $45 \mathrm{~mm} / \mathrm{min}$. The sides and top are exposed to air and a convection heat transfer coefficient of $10 \mathrm{~W} / \mathrm{m}^{2} \mathrm{~K}$ is assumed. The bottom is supported by a cast iron backing plate and hence a high convection heat transfer coefficient of $1000 \mathrm{~W} / \mathrm{m}^{2} \mathrm{~K}$ is assumed. The two heat sources - heat generated by plastic deformation, frictional heat generation and the viscosity were embedded in the simulation as user - defined functions (udf) based on C programming. The tool is rotating at $1100 \mathrm{rpm}$ and held perpendicular to the workpiece. An axial load of $7 \mathrm{kN}$ applied on the tool to complete the welding process.

\section{Experimental Procedure}

In order to validate CFD simulation results, experimental measurements were conducted meticulously. The melting range of AA 7068 is $749-908 \mathrm{~K}$ and the maximum possible temperature during FSW process reported in the literature is approximately $90 \%$ of melting temperature. Therefore, the temperature developed in FSW of AA 7068 must lie in the range of $674-814 \mathrm{~K}$. The simulations for $\mathrm{C} 2$ model predicted peak temperature of $670 \mathrm{~K}$ which falls short of this range and hence this model was excluded from experiments. However, C3 model provided better velocity distribution with particle movement than C2 model resulting in the selection of C3 model for experiments. A semi-automatic friction stirs welding machine of $60 \mathrm{kN}$ capacity was used to join the $6 \mathrm{~mm}$ thick AA 7068-T6 plates of dimensions $100 \mathrm{~mm} \times 50 \mathrm{~mm}$ in butt configuration. The dimensions of the FSW tool and process parameters used are same as that used in the simulation. A photographic image of the FSW tool is shown in Figure 4(a) and fabricated joint is depicted in Figure 4(b). The tool is made of $\mathrm{H} 13$ tool steel. The temperature was measured using a FLUKE thermal imager TiS20. The micro hardness values of the weld joint nugget zone were measured using Mitutoyo micro Vickers hardness testing machine. A load of $1.96 \mathrm{~N}$ was applied for 10 seconds. The specimens extracted from the weld zone were observed under the metallurgical microscope after standard proceduresgrinding, polishing and etching. Keller's reagent was used as the etchant.

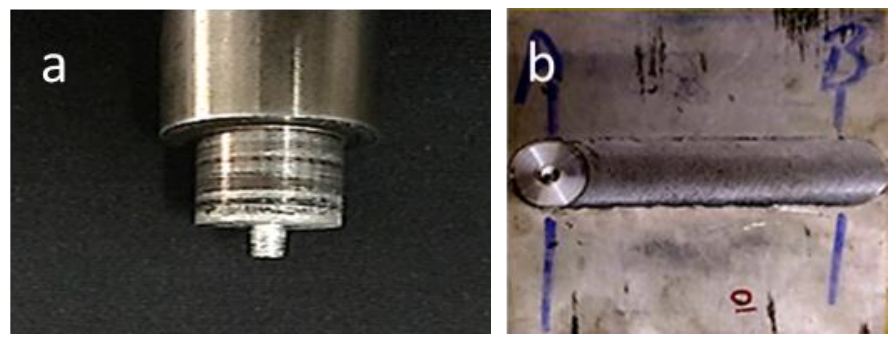

Fig. 4. (a) FSW tool, C3 model, (b) fabricated joint

\section{Results and Discussions}

\subsection{Temperature Contours}

The peak temperature from the simulation and the experiment is given in Table 3. Colegrove et al., [19] used peak temperature for comparing experimental and simulation results. Temperature is highest for the C3 model. The lowest temperature is for $\mathrm{C} 2$ model. The measured temperature is less than that obtained from the simulation and the difference is 22 with an error of $3 \%$. 
Table 3

Peak Temperature

\begin{tabular}{lllll}
\hline Model & C1 & C2 & C3 & Experiment (threaded tool) \\
\hline Temperature (K) & 732 & 670 & 763 & 741 \\
\hline
\end{tabular}

Considering the tool rotation, FS weld plate has two sides- advancing side (AS) and retreating side (RS). The material in the weld zone advances with the tool in the AS whereas material in the RS is pulled behind the tool. Temperature profile taken across a section perpendicular to the welding direction is shown in the Figure 5. For the cases considered, maximum and minimum temperature range is set to $\mathrm{C} 1$ case $(300-732 \mathrm{~K})$. For the three cases temperature profile is asymmetric with respect to the center, i. e in the advancing side temperature distribution spreads over larger area. Higher initial friction in the advancing side than in the retreating side is responsible for this asymmetry. The traverse forces increase from C1 to C3 increasing friction. Moving down in the direction of thickness the width of the nugget zone increases, Width $\mathrm{c}_{2}<$ Width $_{\mathrm{c}_{3}}<$ Width $_{\mathrm{c}_{1} \text {. The region }}$ below the shoulder diameter is termed as TMAZ. The width of TMAZ is less for C2 and C3 models. The HAZ is wider for $\mathrm{C} 2$ followed by $\mathrm{C} 3$ and then $\mathrm{C} 1$ model.

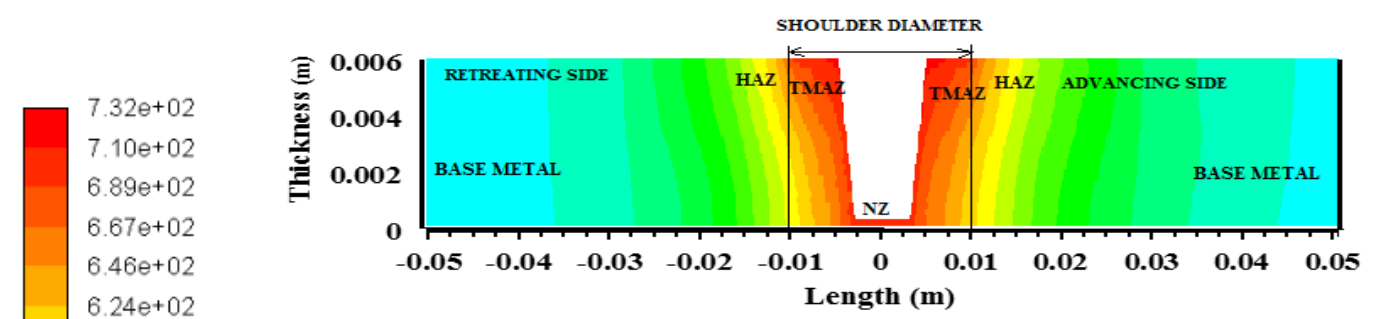

(a)

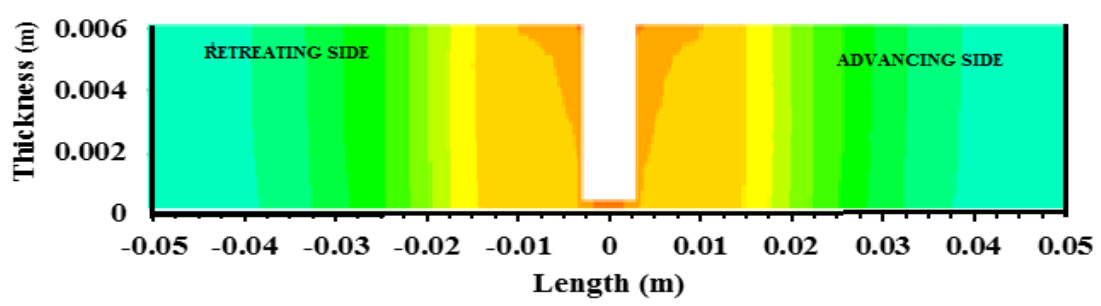

(b)

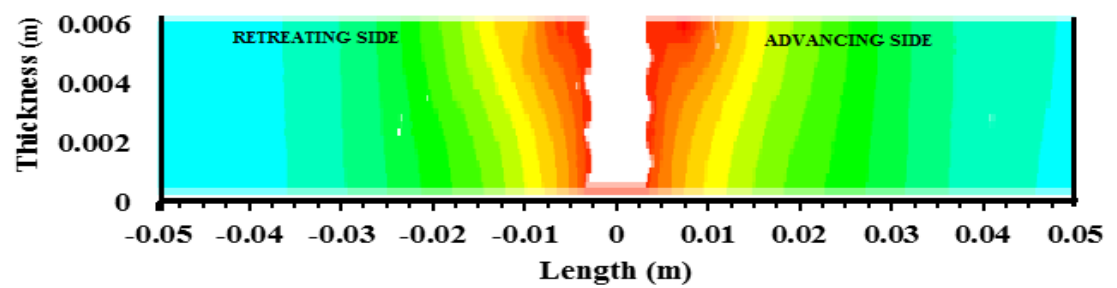

(c)

Fig. 5. Temperature contours on a transverse section for pin profile (a) $C 1$, (b) $C 2$, (c) C3

The temperature contours over the top of the work piece are shown in the Figure 6 . As the tool pin profile changes from $\mathrm{C} 1$ to $\mathrm{C} 3$ it can be seen that the maximum temperature developed increases. The measured values of total contact surface area for the threaded pin are $425.0 \mathrm{~mm}^{2}$, for the conical pin $-417 \mathrm{~mm}^{2}$ and for the cylindrical pin $-422.534 \mathrm{~mm}^{2}$. Because the surface area is the least heat transfer is less for the C1 model. The cooling will be slow. The larger surface area of the C2 model transfer heat at a faster rate uniformly in all directions. The large surface area of C3 model attributed by the presence of threads results in higher amount of heat generation due to friction. These threads in C3 model act like extended surfaces (fins) and release heat to the stirred material inwards. 
Moreover, the heat transfer is not uniform in this region. During rotation, material entrapped between the threads absorbs the generated frictional heat which in turn causes slow cooling in C3 model.

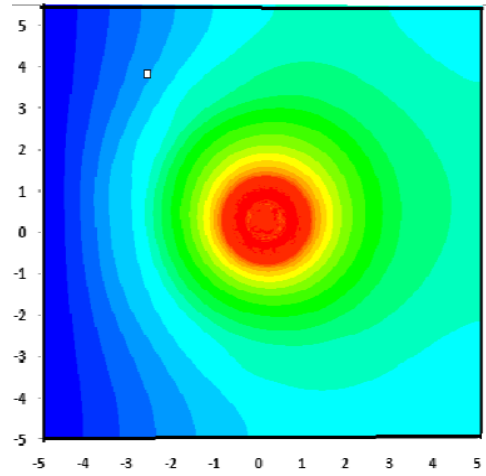

(a)

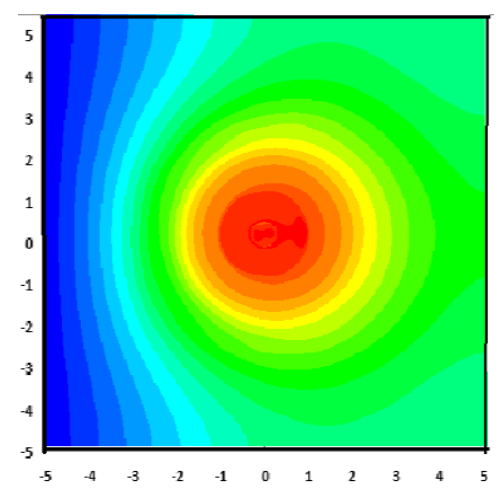

(b)

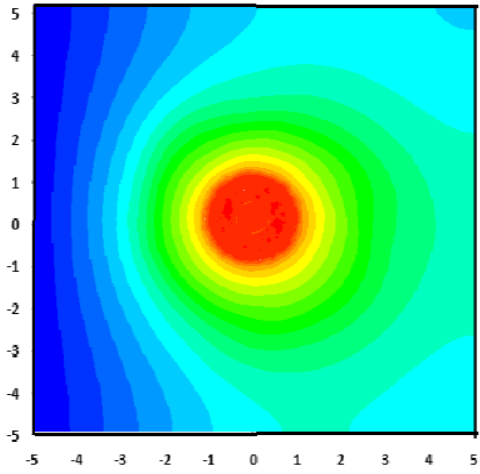

(c)

Temperature range $300-732 \mathrm{~K} \quad$ Temperature range $300-670 \mathrm{~K} \quad$ Temperature range $300-763 \mathrm{~K}$

Fig. 6. Temperature contours on the top surface of the workpiece for the models: (a) C1, (b) C2, (c) $\mathrm{C3}$

\subsection{Material Flow}

The velocity vectors for the three models are depicted in Figure 7. The flow direction of each particle under the shoulder and pin can be seen. The rotation of the shoulder brings material from the AS to the RS. At the same time movement of the pin throws up material from the bottom. The material mixing is dependent on how effectively these movements happen. The movement of the tool is opposed by a layer of stagnant material in front and an opposing force is build up. The temperature developed in the plunging stage softens this layer and reduces the force.

In the previous section it was explained that higher temperatures are developed in C3 model, followed by C1 model and C2. Hence C3 model can transfer particles from AS to RS with less effort compared to other two. There is rotational and translational motion imparted to the material by the threads in the C3 model. These findings are in tune with that reported by Patel et al., [20].

The flow pattern is similar for the three models, but the swirling is different. The thread features on the C3 model provide a helical motion upwards for the particles near its vicinity. For example, path of a particle starting from a much deeper point below the shoulder is marked by black arrows in the Figure $7(\mathrm{c})$. Similar path is traced by a particle well inside the pin region in the Figure $7(\mathrm{a})$. These particles trace a helical path and finally end up at the outer radius of the shoulder. Here mixing is better as such particles from different points mix in different layers. In the Figure $7(b)$ the particle path inside the pin region is circular. However, from the inner shoulder radius, particles are transferred to the outer edge. Thus, mixing is confined to certain planes and there is no particle exchange between different layers. 


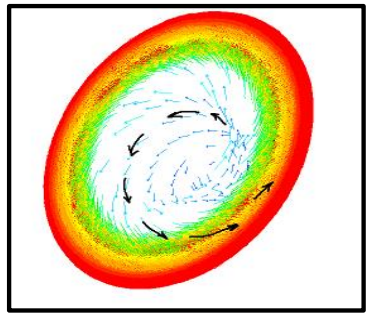

(a)

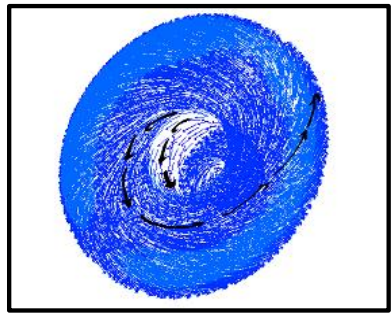

(b)

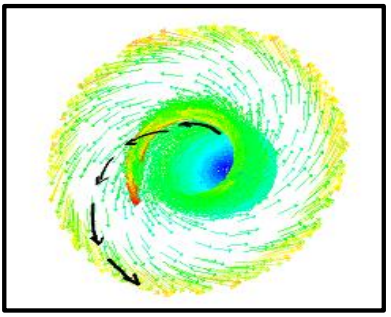

(c)

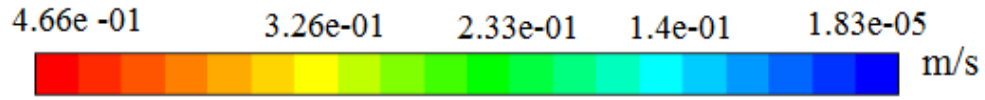

Fig. 7. Velocity vectors for the three models: (a) C1, (b) C2, (c) C3

Figure 8 shows the 3D streamlines through the domain staring from the inlet for the three models. Streamlines are segregated in the retreating side. For the three models the initially straight streamlines are bent around the shoulder. This indicates a circular movement of material below the shoulder. Flow pattern is different in the advancing and retreating sides for the three models. The higher amount of heat generation in model C3 causes the material to stick to the shoulder. Thus, streamlines are closer to shoulder in C3 model. Similarly, in C1 model the streamlines wrap around the tapered pin due to the high heat generation.

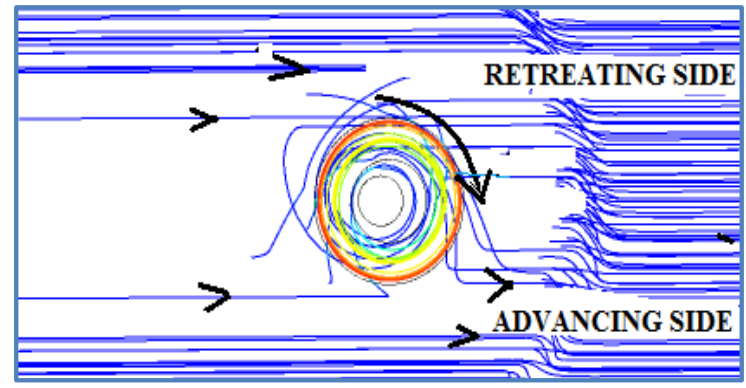

(a)

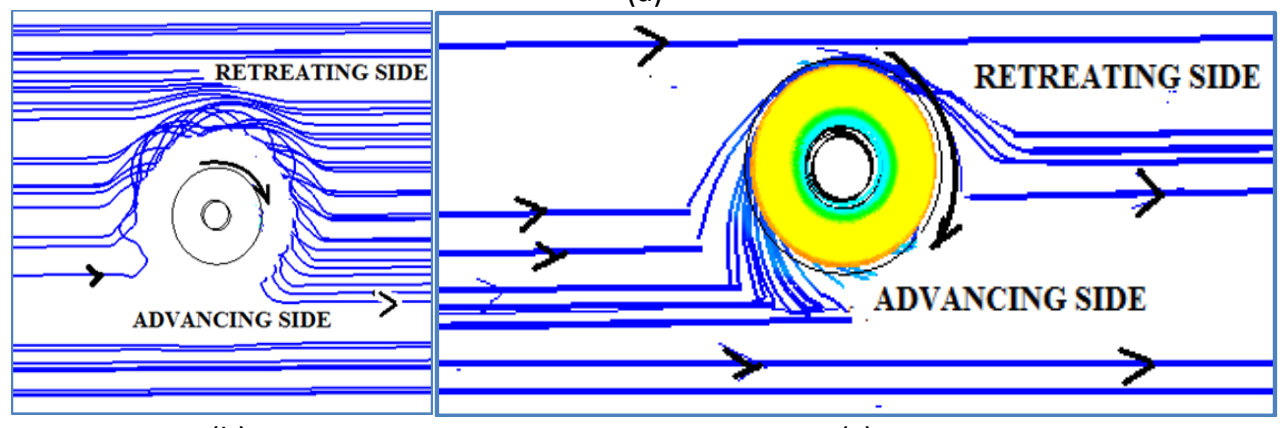

(b)

(c)

Fig. 8. Streamlines for the three models: (a) C1, (b) C2, (c) C3

Figure 9 shows velocity distribution taken on a section perpendicular to the weld direction. For all three models' maximum velocity is occurs below the shoulder edge. The highest flow velocity (1.14 $\mathrm{m} / \mathrm{s}$ ) is same for the three models. There is a small region below the pin where the velocity is zero. If the temperature is not high enough here, root defect (lack of penetration) may develop. Pin profiles that produce more frictional heat can eliminate root defects. For the C3 model there is vertical movement down the thickness imparted by the threads. This movement improves the mixing efficiency. 


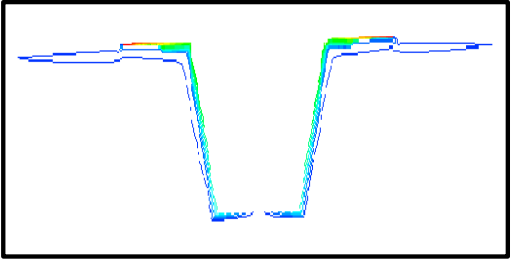

(a)

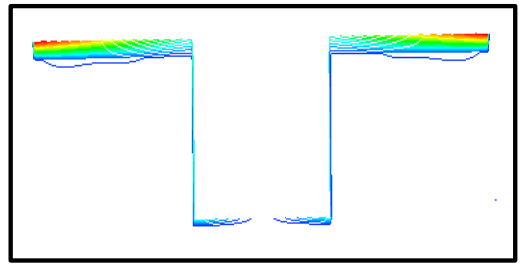

(b)

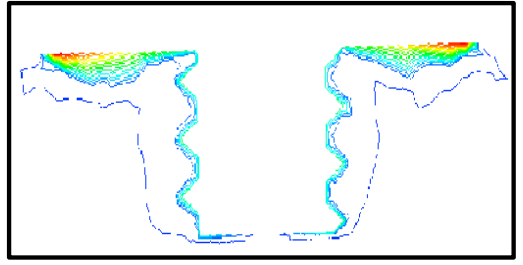

(c)

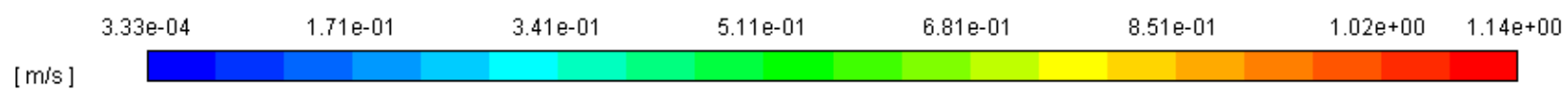

Fig. 9. Velocity distribution on a plane perpendicular to the weld direction (a) $\mathrm{C} 1,(\mathrm{~b}) \mathrm{C2}$, (c) C3

\subsection{Microstructure Analysis}

In the microstructure of FSW joints there are four distinct regions with notable differences. At the center of the weld, the nugget zone (NZ) is subjected to intensive stirring and higher temperatures. A unique feature of this region is the recrystallized fine grains. The region below the shoulder is the thermo mechanically affected zone (TMAZ). The temperature effects are higher, plastic deformation is less compared to NZ. Near to TMAZ temperature effects are spread to some extend far from the tool. This is the heat affected zone (HAZ). Adjacent to the HAZ the base metal remains unaffected. In precipitation hardened alloys, the hardness of each zone is a function of grain size and precipitate distribution.

Figure 10 depicts the microstructure of the different regions of the welded joint fabricated using threaded pin profile. Rolled sheets of AA 7068-T6 were used as the base material. In the base metal microstructure shown in Figure 10(a) elongated grains with homogeneous distribution of precipitates are seen. The presence of precipitates and the strain hardening effect due to rolling gives the base metal, hardness value of $200 \mathrm{HV}$ and UTS of $641 \mathrm{MPa}$. Figure 10(b) depicts the HAZ. Here the grains are elongated; precipitates are distributed homogeneously as in the base metal. Microstructure of the TMAZ is shown in Figure 10(c). The grains are stretched and deformed. Nugget zone is depicted in Figure 10(d). The grain structure is entirely different from that of the base metal. Grains are finer in this region. Precipitates are coarser than the base metal.

The samples have been examined using energy-dispersive X-ray analyses (EDAX) detector attached to the SEM (FE-SEM, Carl Zeiss Sigma) to investigate the chemical compositions (Figure 11). EDX analysis revealed the presence of zinc, magnesium, chromium and copper which are representatives of the equilibrium precipitate.

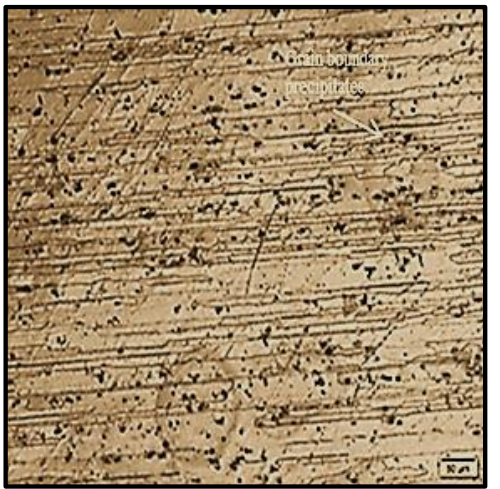

(a)

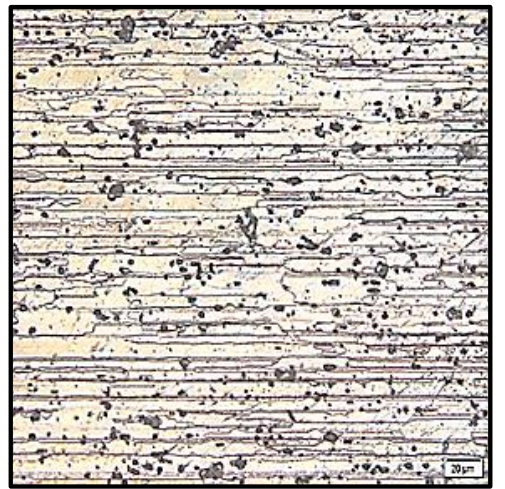

(b) 


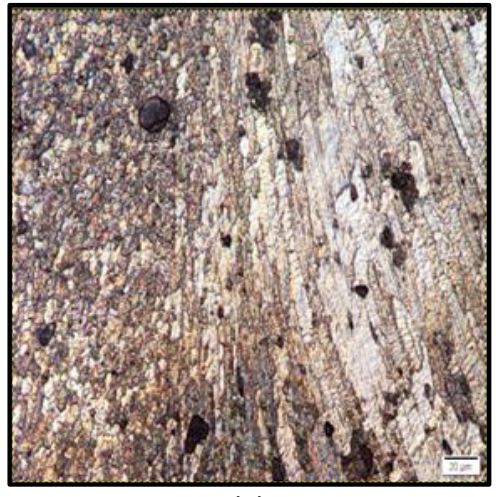

(c)

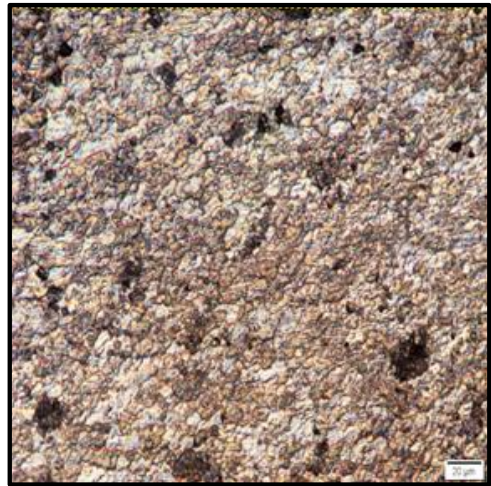

(d)

Fig. 10. (a) Base metal, (b) HAZ, (c) TMAZ, (d) Nugget zone

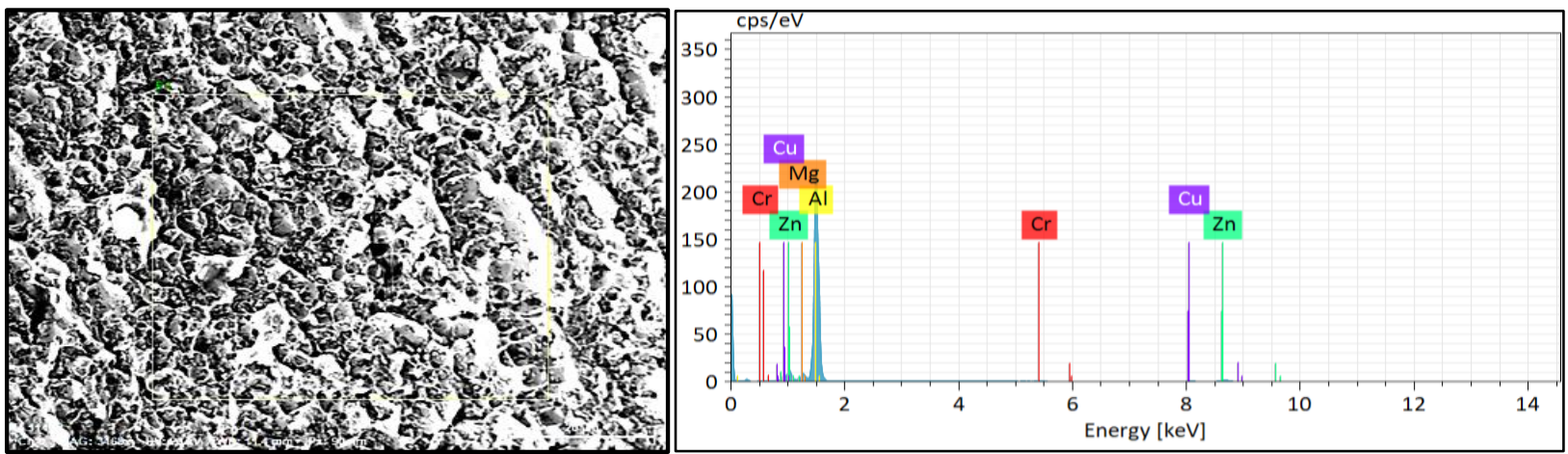

\begin{tabular}{|c|c|c|c|c|c|c|c|}
\hline Element & At. No. & Netto & $\begin{array}{c}\text { Mass } \\
{[\%]}\end{array}$ & $\begin{array}{c}\text { Mass Norm. } \\
{[\%]}\end{array}$ & $\begin{array}{c}\text { Atom } \\
{[\%]}\end{array}$ & $\begin{array}{l}\text { abs. error [\%] } \\
\text { (1 sigma) }\end{array}$ & $\begin{array}{l}\text { rel. error [\%] } \\
\text { (1 sigma) }\end{array}$ \\
\hline Magnesium & 12 & 11320 & 2.79 & 3.13 & 3.56 & 0.18 & 6.57 \\
\hline Aluminium & 13 & 345326 & 81.93 & 91.92 & 94.30 & 3.94 & 4.81 \\
\hline Zinc & 30 & 4116 & 3.37 & 3.78 & 1.60 & 0.13 & 3.97 \\
\hline Copper & 29 & 1102 & 0.82 & 0.92 & 0.40 & 0.06 & 7.35 \\
\hline \multirow[t]{2}{*}{ Chromium } & 24 & 407 & 0.23 & 0.25 & 0.14 & 0.04 & 17.03 \\
\hline & & \multicolumn{2}{|c|}{ Sum 89.13} & \multicolumn{2}{|c|}{100.00100 .00} & & \\
\hline
\end{tabular}

Fig. 11. EDAX result of friction stir weld

\subsection{Hardness Measurements}

Figure 12 shows micro hardness values of different weld regions taken along a section perpendicular to the weld direction. The ' $W$ ' shaped profile is not symmetric about the center. Hardness values are lower in the RS than the AS. The reduction in hardness in the RS is due to the lack of proper coalescence of material in that zone. The hardness values range between $149.2 \mathrm{HV}$ and $167 \mathrm{HV}$. The hardness of base metal AA 7068-T6 is $200 \mathrm{HV}$. The dislocations resulted from rolling operation and the precipitates formed after precipitation hardening increases hardness of the base metal. However, the high heat input in FSW relieves the strain hardening effects of the base metal. Thus, hardness of the different regions of weld zone is lower than the base metal. The nugget zone (NZ) hardness is $165 \mathrm{HV}$. The average hardness of TMAZ falls to $159.2 \mathrm{HV}$ in AS and $156.22 \mathrm{HV}$ in the RS. The lowest hardness values measured are 149.2 in the RS and $152 \mathrm{HV}$ in the AS. This is the interface region between TMAZ and the heat affected zone (HAZ). There is a sharp increase in hardness on both sides beyond the interface of HAZ and TMAZ. Beyond this region hardness further increases on both sides approximating a straight line. The results of hardness measurements are in 
good agreement with the microstructure. The microstructure of the HAZ shows elongated grains and precipitates. This is the reason for the lowering of hardness in HAZ. In the TMAZ precipitates are more clustered, grains are deformed and elongated hence lower hardness. Higher hardness of NZ has resulted from finer grain size.

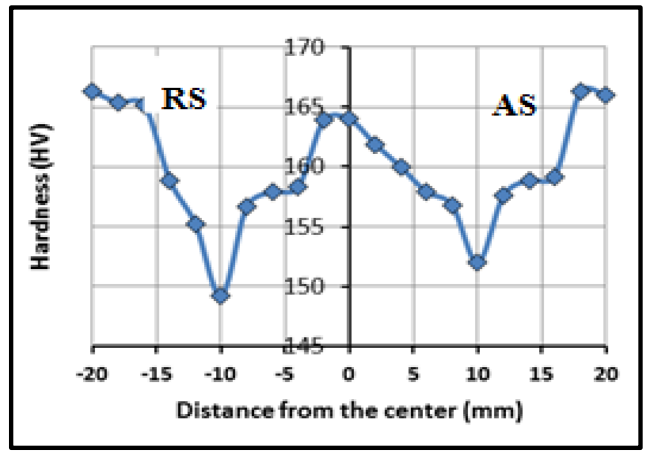

Fig. 12. Hardness Profile

\section{Conclusions}

A 3D CFD model is developed to study the effect of tool pin profile on the flow field and temperature field in the FSW of AA 7068 alloy. Three pin profiles were considered- Conical (C1 model), Cylindrical (C2 model) and straight cylindrical threaded (C3 model). RNG k- $\varepsilon$ turbulence model is used for the simulations. The peak temperatures, temperature distributions and the velocity profile of the three models were compared. The peak temperature is higher and cooling is faster for C3 model. The velocity profile proposes a better mixing in C3 model. Hence C3 model may give good microstructure and mechanical properties to FSW joints.

Based on the numerical results, C3 model is selected for the fabrication of AA 7068-T6 joints. The welding was performed successfully at a rotational speed of $1100 \mathrm{rpm}$, transverse speed of 45 $\mathrm{mm} / \mathrm{min}$ and axial load of $7 \mathrm{kN}$. The microstructure studies were made and hardness of the welded region was measured. The prepared welds were free of defects in the macro and micro levels. The minimum hardness value obtained at the interface $(149.2 \mathrm{HV})$ is $71 \%$ of that of the base metal. This value indicates that the effect of precipitation hardening is not lost at the temperature developed. The numerical and experimental study suggest that straight cylindrical threaded pin (C3 model) is the ideal pin profile to be used in the friction stir welding of AA 7068-T6 at a welding speed of $45 \mathrm{~mm} / \mathrm{min}$, tool rotational speed of $1100 \mathrm{rpm}$ and axial load of $7 \mathrm{kN}$.

The developed model can be used for parameter optimisation avoiding time consuming and expensive experimental trials.

\section{References}

[1] Bayazid, Seyed Mahmoud, Mahmud Mohamed Heddad, and Ibrahim Cayiroglu. "A review on friction stir welding, parameters, microstructure, mechanical properties, post weld heat treatment and defects." Material Science and Engineering International Journal 2, no. 4 (2018): 116-126. https://doi.org/10.15406/mseij.2018.02.00044

[2] Rudrapati, Ramesh. "Recent advances in joining of aluminum alloys by using friction stir welding." Mass Production Processes (2019). https://doi.org/10.5772/intechopen.89382

[3] Minnicino, Michael, David Gray, and Paul Moy. Aluminum alloy 7068 mechanical characterization. Army Research Lab Aberdeen Proving Ground Md Weapons And Materials Research Directorate, 2009. https://doi.org/10.21236/ADA506416

[4] Abd El-Hameed, Afaf M., and Y. A. Abdel-Aziz. "Aluminium Alloys in Space Applications: A Short Report." Journal of Advanced Research in Applied Sciences and Engineering Technology 22, no. 1 (2021): 1-7. 
[5] Giordano, Giuseppe. "The Influence of the Details of Chemical Composition on the Performance of Quality Extrusions." PubliTec Online, September 6, 2018. https://aluminiumandalloys.com/the-influence-of-the-details-ofchemical-composition-on-the-performance-of-quality-extrusions.

[6] Meyghani, Bahman, and Chuansong Wu. "Progress in thermomechanical analysis of friction stir welding." Chinese Journal of Mechanical Engineering 33, no. 1 (2020): 12. https://doi.org/10.1186/s10033-020-0434-7

[7] Mishra, Akshansh, and Devarrishi Dixit. "Friction Stir Welding of Aerospace Alloys." Journal of Mechanical Engineering 48, no. 1 (2018): 37-46. https://doi.org/10.3329/jme.v48i1.41093

[8] Li, Hongjun, Jian Gao, Qinchuan Li, Alexander Galloway, and Athanasios Toumpis. "Effect of friction stir welding tool design on welding thermal efficiency." Science and Technology of Welding and Joining 24, no. 2 (2019): $156-162$. https://doi.org/10.1080/13621718.2018.1495868

[9] Tamadon, A., D. J. Pons, and D. Clucas. "Analogue Modelling of Flow Patterns in Bobbin Friction Stir Welding by the Dark-Field/Bright-Field Illumination Method." Advances in Materials Science 20, no. 1 (2020): 56-70. https://doi.org/10.2478/adms-2020-0003

[10] Zhu, Zhi, Min Wang, Huijie Zhang, Xiao Zhang, Tao Yu, and Zhenqiang Wu. "A finite element model to simulate defect formation during friction stir welding." Metals 7, no. 7 (2017): 256. https://doi.org/10.3390/met7070256

[11] Martinez, N., N. Kumar, R. S. Mishra, and K. J. Doherty. "Effect of tool dimensions and parameters on the microstructure of friction stir welded aluminum 7449 alloy of various thicknesses." Materials Science and Engineering: A 684 (2017): 470-479. https://doi.org/10.1016/j.msea.2016.12.077

[12] Gadakh, Vijay Shivaji, and Kumar Adepu. "Heat generation model for taper cylindrical pin profile in FSW." Journal of Materials Research and Technology 2, no. 4 (2013): 370-375. https://doi.org/10.1016/j.jmrt.2013.10.003

[13] Hamzah, Mushtaq Talib, and Ali Lateef Tarish. "Numerical Study of The Effect of Corrugated Wall on The Turbulent Forced Convective Heat Transfer and Fluid Flow Through a Forward-facing Step Channel." Journal of Advanced Research in Fluid Mechanics and Thermal Sciences 67, no. 1 (2020): 33-42.

[14] Yusof, Siti Nurul Akmal, Yutaka Asako, Nor Azwadi Che Sidik, Saiful Bahri Mohamed, and Wan Mohd Arif Aziz Japar. "A Short Review on RANS Turbulence Models." CFD Letters 12, no. 11 (2020): 83-96. https://doi.org/10.37934/cfdl.12.11.8396

[15] Warjito, Warjito, Sanjaya BS Nasution, Muhammad Farhan Syahputra, Budiarso Budiarso, and Dendy Adanta. "Study of Turbulence Model for Performance and Flow Field Prediction of Pico Hydro Types Propeller Turbine." CFD Letters 12, no. 8 (2020): 26-34. https://doi.org/10.37934/cfdl.12.8.2634

[16] Tiwari, Avinish, Pardeep Pankaj, Saurav Suman, and Pankaj Biswas. "CFD Modelling of Temperature Distribution and Material Flow Investigation During FSW of DH36 Shipbuilding Grade Steel." Transactions of the Indian Institute of Metals 73, no. 9 (2020): 2291-2307. https://doi.org/10.1007/s12666-020-02030-7

[17] Mills, Kenneth C. Recommended values of thermophysical properties for selected commercial alloys. Woodhead Publishing, 2002. https://doi.org/10.1533/9781845690144

[18] Chen, Gaoqiang, Qingxian Ma, Shuai Zhang, Jianjun Wu, Gong Zhang, and Qingyu Shi. "Computational fluid dynamics simulation of friction stir welding: A comparative study on different frictional boundary conditions." Journal of Materials Science \& Technology 34, no. 1 (2018): 128-134. https://doi.org/10.1016/i.jmst.2017.10.015

[19] Colegrove, Paul A., Hugh R. Shercliff, and Rudolf Zettler. "Model for predicting heat generation and temperature in friction stir welding from the material properties." Science and Technology of Welding and Joining 12, no. 4 (2007): 284-297. https://doi.org/10.1179/174329307X197539

[20] Patel, Vivek, Wenya Li, Guoqing Wang, Feifan Wang, Achilles Vairis, and Pengliang Niu. "Friction stir welding of dissimilar aluminum alloy combinations: State-of-the-art." Metals 9, no. $3 \quad$ (2019): 270. https://doi.org/10.3390/met9030270 